九州大学学術情報リポジトリ

Kyushu University Institutional Repository

\title{
Base-catalyzed Intramolecular Rearrangement of Trimethylamine $\mathrm{N}$-oxide
}

Harada, Katsuhiko

Laboratory of Sericultural Chemistry, Faculty of Agriculture, Kyushu University

Aso, Yoichi

Laboratory of Sericultural Chemistry, Faculty of Agriculture, Kyushu University

Hayashi, Katsuya

Laboratory of Sericultural Chemistry, Faculty of Agriculture, Kyushu University

https://doi.org/10.5109/22878

出版情報：九州大学大学院農学研究院紀要. 19 (4)，pp.159-168，1975-06. Kyushu University バージョン：

権利関係 : 


\title{
Base-catalyzed Intramolecular Rearrangement of Trimethylamine $\mathbf{N}$-oxide
}

\author{
K atsuhiko Harada*, $Y$ oichi Aso and $K$ atsuya $H$ ayashi \\ Laboratory of Sericultural Chemistry, Faculty of \\ Agriculture, Kyushu University, Fukuoka \\ (Received March 3, 1975)
}

\begin{abstract}
The catalytic role of acid and base in the rearrangement and the following decomposition of trimethylamine $\mathrm{N}$-oxide to formaldehyde and dimethylamine has been investigated. The catalyzer which decomposed the $\mathrm{N}$-oxide most extensively was tris (hydroxymethyl) aminomethane-malonate system, while several other tris (hydroxymethyl) aminomethane-dibasic carboxylic acid systems exhibited appreciable catalytic activities. Specific acid and base, hydrogen ion and hydroxide ion, scarcely showed the catalytic activity in the $\mathrm{pH}$ region from 0 to 14 . The optimum $\mathrm{pH}$ of tris (hydroxymethyl) aminomethane-malonate system for the decomposition of trimethylamine $\mathrm{N}$ oxide was 11 and the amounts of the products, formaldehyde and dimethylamine, bore an equimolar relation to each other. On the other hand, several assumed schemes were simulated to elucidate the catalytic mechanism of tris (hydroxymethyl) aminomethane-malonate system.

Based upon the reaction mechanism presumed from the experimental results, it has been concluded that the catalyzed rearrangement of trimethylamine $\mathrm{N}$-oxide may occur through an intermediate to yield dimethylaminomethylol which gives spontaneously formaldehyde and dimethylamine as final products. In addition, the mechanism of rearrangement step was discussed from the standpoint of role of acid-base catalysis with emphasizing the action of base or hydride ion.
\end{abstract}

\section{INTRODUCTION}

It has been well known that trimethylamine N-oxide (TMO) is distributed widely in tissues of many species of fish and shells (Yamada, 1967). The oxide is cleaved by the action of a certain enzyme (Yamada, 1968) or non-enzymatic catalysis (Vaisey, 1956 ; Soudan, 1959, 1961; Craig et al., 1961; Ferris et al., 1967; Hayashi et al., 1964; Otsuka, personal communication) into formaldehyde (FA) and dimethylamine (DMA). The reaction mechanism of formations of FA and DMA from TMO in enzymatic reaction has been preliminarily investigated by Yamada (1968). Contrarily, the mechanism has been fairly well examined in the non-enzymatic reactions (Vaisey, 1956; Craig et al., 1961; Ferris et al., 1967). The majority of presented mechanisms is containing the reaction step of the formation of an intermediate dimethylaminomethylol (Fish et al., 1956; Sweely et al., 1957 ; Frisell et al., 1959).

* Visiting Research Associate from Department of Food Science and Technology, The Shimonoseki University of Fisheries, Shimonoseki. 
Harada (unpublished data) observed that the participation of reduced methylene blue or reduced flavin nucleotide (co-factor) was required in the enzymatic reaction. The decomposition of TMO to FA and DMA is purely unimolecular reaction and there is any exchange of matter with surrounding medium. Therefore, the role of the reduced co-factors may not be the entire donation of electrons or hydride ion (reduction), but the circulation of electrons through the TMO molecule to generate the polarization of electron distribution in the molecule. If this is the case, acid-base species may exhibit also the catalytic activity to some extents for the decomposition of TMO, because one of the catalytic roles of acid-base species has been known to polarize the electron distribution of a substrate molecule. Thus, the present study was focused to the observation of action of acid-base catalyzer toward the decomposition of TMO in connection with the elucidation of the mechanism of catalysis in the enzymatic reaction.

\section{EXPERIMENTAL}

\section{Materials}

Substrate : Trimethylamine $N$-oxide $\cdot 2 \mathrm{H}_{2} \mathrm{O}$ was of guaranteed reagent grade, purchased from Wako Pure Chemical Industries, Ltd.

Catalyzer: Lewis acids were aluminum trichloride and boron trifluoride etherate, purchased from Wako Pure Chemical Industries, Ltd. Specific acid and base were hydrochloric acid and sodium hydroxide. General acid-bases were several buffer solutions. Tris-carboxylate buffers were most frequently used.

\section{Methods}

Assay of catalytic activity: A 50 umole of TMO was added to $5 \mathrm{ml}$ of chloroform containing $1 \mathrm{mmole}$ of aluminum trichloride or $5 \mathrm{ml}$ of boron trifluoride etherate, while for acid-base catalysis $1 \mathrm{ml}$ of $0.2 \mathrm{M}$ TMO solution (200 $\mu$ mole) was added to $10 \mathrm{ml}$ of buffer solution. The mixture solution was then incubated at $80^{\circ} \mathrm{C}$ for desired periods, and an aliquot was subjected to the determinations of FA and DMA.

Determination of FA and DMA : The amounts of FA and DMA were determined by the methods of Nash (1953) and Dyer (1945), respectively.

Computer simulation: Computer simulations were performed with FACOM 230-75 using Graphic Display GDP F6233A in the Computer Center, Kyushu University.

\section{RESULTS}

\section{Catalytic activity of Lewis acids}

The catalytic formations of FA and DMA from TMO with Lewis acids are shown in Fig. 1. As seen in the figure, the formations of FA and DMA are observed only in the solution of boron trifluoride, but not in the solution of aluminum trichloride.

Abbreviations are ; TMO: trimethylamine N-oxide, FA : formaldehyde, DMA : dimethylamine, Tris : tris (hydroxymethyl) aminomethane. 


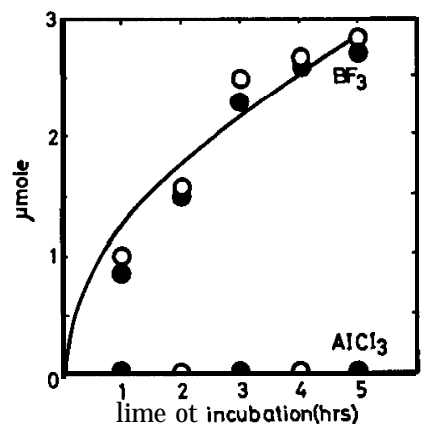

Fig. 1. Catalytic formations of FA and DMA from TMO by Lewis acids. O: FA, ๑ : DMA.

\section{Catalytic activity of specific acid-base}

As shown in Fig. 2, the formations of FA and DMA in the solution of hydrochloric acid and sodium hydroxide were found to be very faint even below $\mathrm{pH} 1$ and above $\mathrm{pH}$ 13. This may mean that TMO is not in the methylol form which has been believed to decompose easily to FA and DMA in acid or alkaline medium.

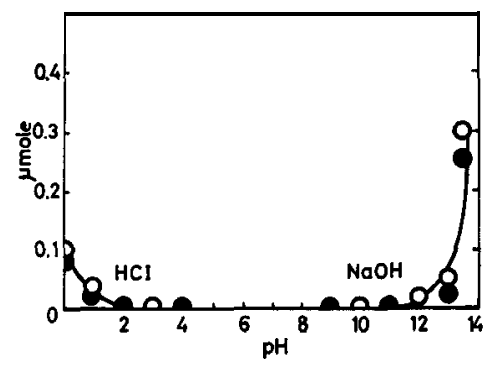

Fig. 2. Catalytic formations of FA and DMA from TMO in specific acid and base solutions. Reaction mixture was incubated at $80^{\circ} \mathrm{C}$ for $40 \mathrm{hrs}$. 0 : FA, $\bullet$ : DMA.

\section{Catalytic activity of general acid-base}

The formations of FA and DMA in many kinds of buffer solutions were, first of all, generally surveyed. The results are shown in Fig. 3. The catalytic formations of FA and DMA were observed in several buffer solutions, though the extents were not exceeded $1 \%$ of initial amount of TMO. However, it was expected that the formations of FA and DMA in the Tris-maleate system may increase in high $\mathrm{pH}$ region. To confirm the expectation, the $\mathrm{pH}$-dependence of catalytic action of Tris-maleate system was examined in $\mathrm{pH}$ region from 5 to 12. The result obtained is shown in Fig. 4. It was noted that the formations of FA and DMA occurred considerably at pH 11. In connection with the catalytic activity of Tris-maleate system, the formations of FA and DMA in the medium containing other dibasic acid used instead of maleate were surveyed. The results are presented in Fig. 5. The formations were observed most strongly in $\mathrm{pH}$ 

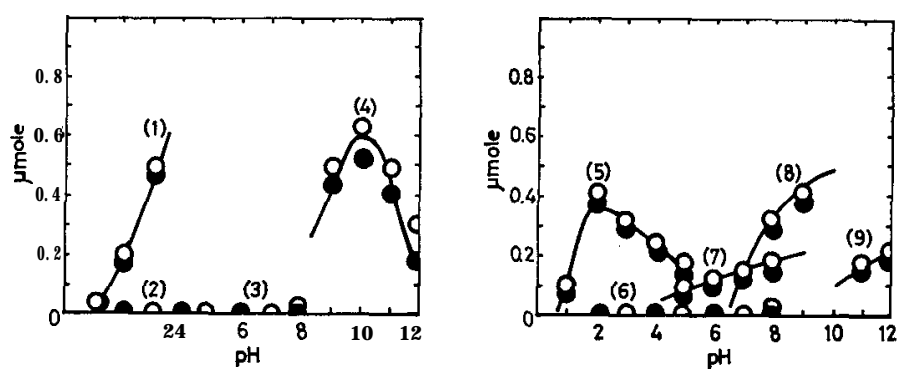

Pi g. 3. Catalytic formations of FA and DMA from TMO in buffer solutions. (1)Glycine$\mathrm{NaCl}-\mathrm{HCl}(\mathrm{pH} 1.1-3.0)$, (2) Sodium citrate-HCl (pH 1.1-4.0), (3) Sodium phosphate dibasic-potassium phosphate monobasic $(\mathrm{pH} 5.0-8.0)$, (4) Glycine- $\mathrm{NaCl}-\mathrm{NaOH}(\mathrm{pH}$ 9.0-12.0), (5) HCl-sodium acetate $(\mathrm{pH} 1.0-5.0)$, (6) Citric acid-sodium phosphate dibasic ( $\mathrm{pH} 2.2-8.0)$, (7) Tris-WC1 ( $\mathrm{pH} 7.0-9.0$ ), (8) Tris-maleic acid- $\mathrm{NaCl}(\mathrm{pH} 5.0-8.0$ ), (9) $\mathrm{NaOH}$-sodium phosphate dibasic $(\mathrm{pH} 11.0-12.0)$. Reaction mixture was incubated at $80^{\circ} \mathrm{C}$ for $40 \mathrm{hrs.} 0$ : FA, $\bullet$ : DMA.

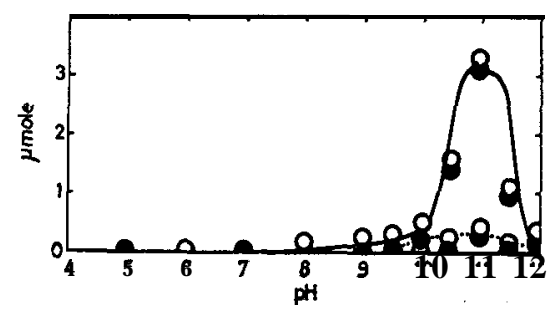

Fig. 4. Catalytic formations of FA and DMA in Tris buffer. Solid line: Trismaleic acid- $\mathrm{NaOH}$, Dotted line :Tris- $\mathrm{NaOH}$. o: FA, $\bullet$ : DMA.

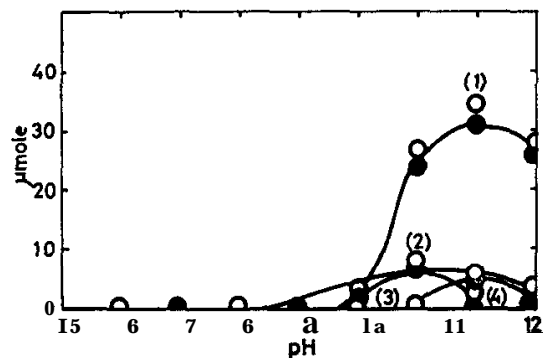

Fig. 5. Effect of dibasic acids on the catalytic formations of FA and DMA in Tris buffer. (1) Malonic acid, (2) Azelaic acid, (3) Succinic acid, (4) Oxalic acid. O: FA, ๑: DMA.

region from 10 to 11.5 regardless of kind of dibasic acids. The formations of FA and DMA in Tris-malonate system was superior to those in other Trisdibasic acid systems.

\section{Catalytic activity in Tris-malonate system}

In Tris-malonate system of which the $\mathrm{pH}$ values were adjusted by the addi- 
tion of sodium hydroxide, the formations of FA and DMA were estimated with changing the concentrations of the catalyzer and the substrate. The results are shown in Figs. 6 and 7. In the early stages of the reaction, it was found that the time-course of the formations exhibited a clear induction periods; at low concentration of the catalyzer, induction periods (lag-time) extended to $20 \mathrm{hrs}$ of incubation. The amounts of product held an equimolar relation to each other. In the late stages of the reaction, such the relation was broken due to the loss of formed FA.

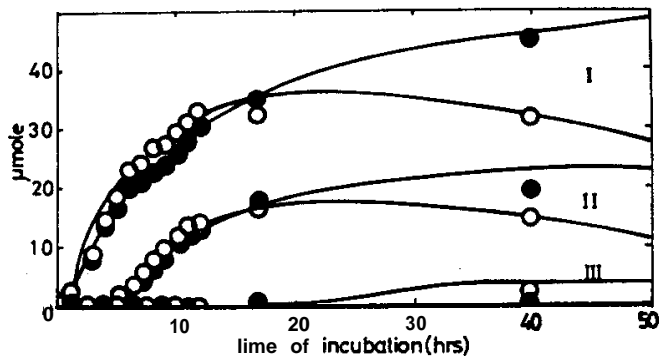

Fig. 6. Formations of FA and DMA in Tris-malonate system. Concentrations of Trismalonate (catalyzer) were I : $0.152 \mathrm{M}$, II : $0.091 \mathrm{M}$, III : $0.03 \mathrm{M}$. Incubated at $80^{\circ} \mathrm{C} . \mathrm{O}$ : FA, $\bullet:$ DMA.
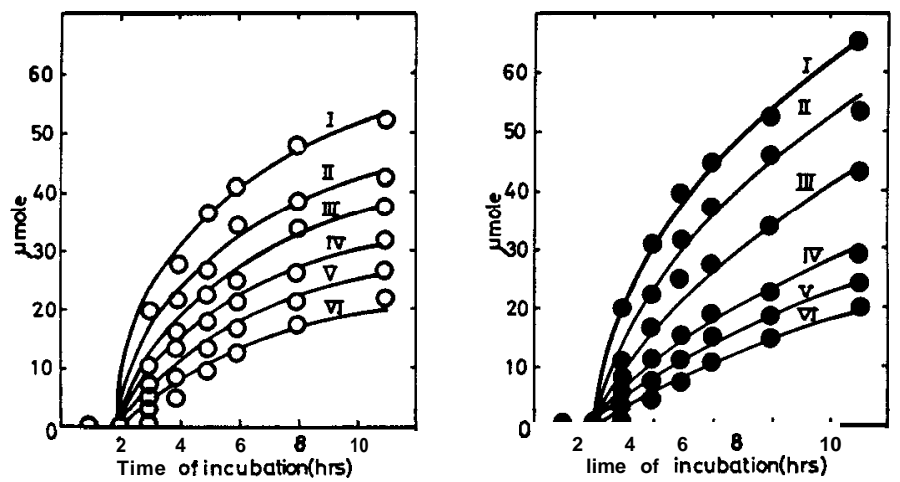

Fig. 7. Formations of FA and DMA in $0.152 \mathrm{M}$ Tris-malonate system. Concentrations of 'TMO of I, II, III, IV, V and VI were 0.182, 0.091, 0.046, 0.0182. 0.0091 and $0.0046 \mathrm{M}$, respectively. O: FA, : DMA.

\section{Computer simulation}

To elucidate the reaction pathway of TMO decomposition by the base (Trismalonate system) catalysis, the several schemes were assumed and simulated. As a result of simulation, several schemes which can principly explain the characteristic features of time-course in the base-catalyzed decomposition of TMO were selected. Typical schemes thus selected are shown in Scheme 1. The results of the simulation on the selected schemes are shown in Figs. 8 and 9. The rate constants used for the computation of time-courses shown in the figures are 
(1)
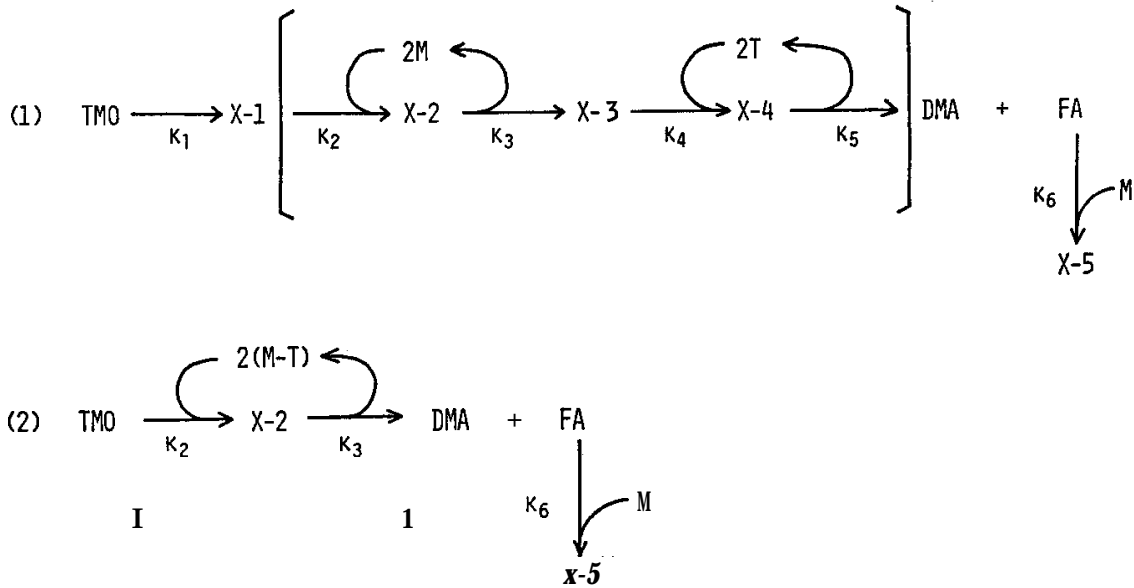

Scheme 1. Assumed schemes of Tris-malonate catalyzed reaction. $X-1,2,3$ and 4 : intermediate, X-5 : condensed product, $\mathrm{T}$ : Tris component, $\mathrm{M}:$ malonate.
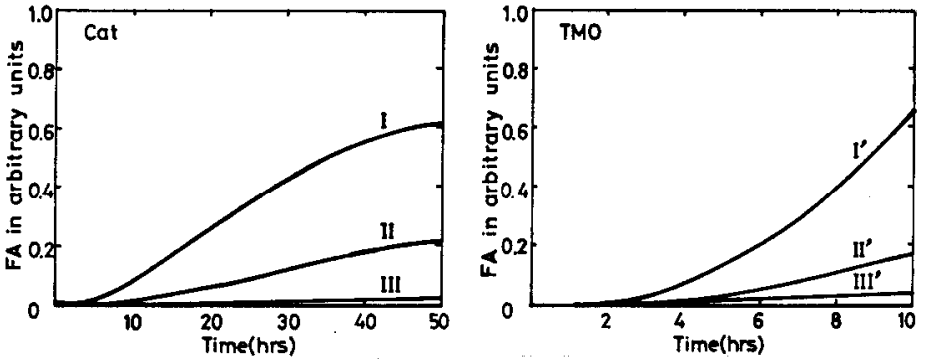

Fig. 8. Simulated time-course for Scheme-(1). Cat: Catalyzer concentrations were changed as follows under fixing substrate concentration at $0.182 \mathrm{M}$, I : $0.152 \mathrm{M}$, II : $0.091 \mathrm{M}$, III: $0.03 \mathrm{M}$. TMO: Substrate concentrations were changed as follows under fixing catalyzer concentration at 0.125 M. I': $0.182 \mathrm{M}$, II': $0.091 \mathrm{M}$, III': $0.046 \mathrm{M}$.
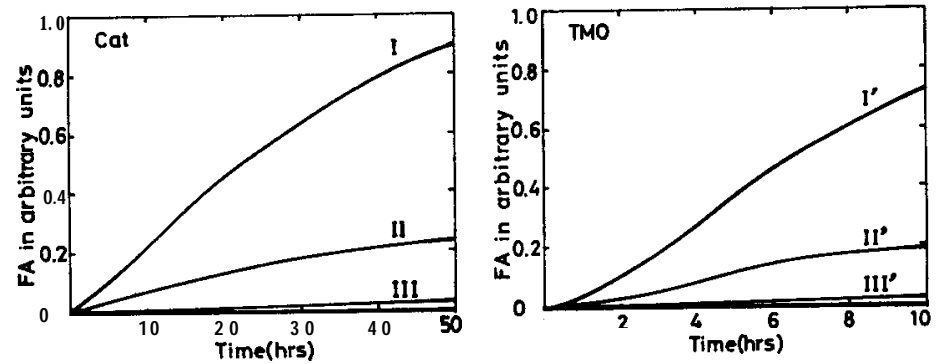

Fig. 9. Simulated time-course for Scheme-(Z). Notations are the same as those in Fig. 8.

listed in Table 1. It is obvious, as can be seen in the figures, that the timecourses computed with Scheme-(l) are most fittable to the experimental data shown in Figs. 6 and 7. 
Table 1. Rate constants used for computation.

\begin{tabular}{|c|c|c|c|c|}
\hline \multirow{2}{*}{ Scheme } & \multicolumn{2}{|c|}{ Catalyzer } & \multicolumn{2}{|c|}{ TMO } \\
\hline & (1) & (2) & (1) & (2) \\
\hline$k_{1}\left(\sec ^{-1}\right)$ & $0.333 \times 10^{-4}$ & & $0.333 \times 10^{-4}$ & - \\
\hline$k_{2}\left(\mathrm{M}^{-1} \sec ^{-1}\right)$ & $0.333 \times 10^{-3}$ & $0.333 \times 10^{-5}$ & $0.333 \times 10^{-3}$ & $0.167 \times 10^{-3}$ \\
\hline$k_{3}\left(\sec ^{-1}\right)$ & $0.333 \times 10^{-2}$ & $0.333 \times 10^{-3}$ & $0.333 \times 10^{-2}$ & $0.167 \times 10^{-3}$ \\
\hline$k_{4}\left(\mathrm{M}^{-1} \sec ^{-1}\right)$ & $0.333 \times 10^{-3}$ & & $0.333 \times 10^{-3}$ & \\
\hline$k_{5}\left(\sec ^{-1}\right)$ & $0.333 \times 10^{-2}$ & - & $0.333 \times 10^{-2}$ & \\
\hline$k_{6}\left(\mathrm{M}^{-1} \sec ^{-1}\right)$ & $0.333 \times 10^{-3}$ & $0.333 \times 10^{-4}$ & $0.333 \times 10^{-3}$ & $0.167 \times 10^{-3}$ \\
\hline
\end{tabular}

\section{DISCUSSION}

Vaisey (1956), Craig et al. (1961)and Ferris et al. (1967) studied the catalytic actions of iron compounds and Otsuka (personal communication) investigated the decomposition of TMO in the presence of acetic anhydride. Catalytic cleavage of TMO by ferrous or ferric compounds gives the oxido-reduction products, trimethylamine and formic acid, in addition to the normal products, FA and DMA. Since the enzymatic decomposition of TMO gives stoichiometrically equimolar amounts of FA and DMA, but not trimethylamine (Harada, unpublished data), it is not believed that the enzyme provides for a similar catalytic mechanism to that by which iron compound exerts its catalytic activity.

In the enzymatic reaction, it was not observed that the change of co-factor reduced flavin nucleotide or reduced methylene blue to their oxidation forms took place incidentally to the decomposition of the substrate TMO. Since the enzymatic reaction was conducted in anaerobic milieu, there might not be autoxidation of reduced co-factor during the enzymatic reaction. Furthermore, it is clear that the decomposition TMO to FA and DMA is purely unimolecular reaction.

Thus, the catalytic action of enzyme and co-factors toward the substrate may be assumed to occur via (a) the enzyme protein moiety acts as acid-base catalyzer and the co-factor is not participating directly in the reaction steps, or (b) both enzyme protein and co-factor act as acid-base catalyzer cooperatively. To approve the above assumptions or to justify the possibility of the above assumptions, catalytic actions of non-enzymatic acid-base species were examined.

Specific acid-base, hydrogen and hydroxide ion, exhibited very low activity in $\mathrm{pH}$ region from 0 to 13 as shown in Fig. 2. It had been supposed that an amine $\mathrm{N}$-oxide has partly the methylol structure in aqueous solution. If this is the case, trimethylamine $\mathrm{N}$-oxide must be rapidly decomposed to FA and DMA in the presence of moderate concentration of hydrogen ion or hydroxide ion. The experimental results exclude the methylol structure of TMO in aqueous solution.

It should be emphasized that the some buffer solutions exhibited more catalytic activity in various pa-regions than specific acid-base did. Especially, 
Tris-malonate system showed a remarkable catalytic activity around $\mathrm{pH} 11$. Since the catalytic groups of Tris-malonate system around pH 11 are assumed to be amino group and oxyanions of Tris component and carboxylate ions of malonate, the mode of catalysis of the Tris-malonate system is considered to be general base catalysis.

Although optimum $\mathrm{pH}$ values and the pH-regions for enzymatic activity $(\mathrm{pH}$ 5.0 and $\mathrm{pH} 3-7)$ and for Tris-malonate system ( $\mathrm{pH} 11$ and above $\mathrm{pH}$ 9.5) were quite different to each other, the results on the model system infer that the mode of enzymatic catalysis appears to be also general acid-base catalysis. From the above viewpoint, the mode of the action of reduced methylene blue or reduced flavin nucleotide is presumed unitedly to be general base catalysis ; i.e., reduced co-factor may act on the intramolecular rearrangement and the following decomposition as catalyzer to donate or to withdraw the electron pair or hydride ion to or from the TMO molecule.

The decomposition of TMO to FA and DMA may be consisted of two chemical events; intramolecular rearrangement to form the methylol structure (III or III') and the spontaneous cleavage of methylol compound to FA and DMA. In intramolecular rearrangement, transient (intermediate) structure with threemembered ring (II) has been generally postulated as shown in the following equation.

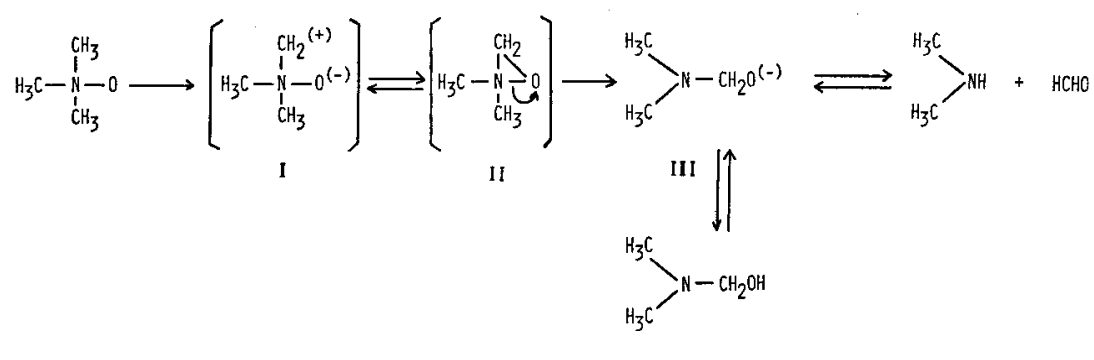

III'

A supposed structure existing just before the three-membered ring structure may have zwitter ion in the molecule (I). Thus, it is very likely that the catalyzer assists the polarization of electron distribution to form the zwitter ion structure. The detailed mechanism of catalyzer action may, therefore, be represented by the following equations (p. 167).

General base in the enzyme protein may either withdraw the proton on methyl group to form the active methylene or donate the electron pair on oxygen atom to form oxyanion. Reduced co-factor may donate hydride ion (a kind of base) which acts either on methyl group or on oxygen atom in similar way to the base. It should be noted, however, that zwitter ion does not necessarily have the structure shown in the equations, but it might also have another structure in which methylene group accomodates negative and oxygen atom has positive charge. Both types of zwitter ion structure are kinetically indistinguishable.

The characteristic features of time-course of the formations FA and DMA in the reaction catalyzed by Tris-malonate system are the appearance of clear in- 
(A) Base

(a)

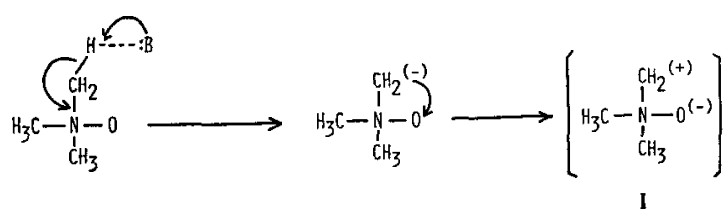

(b)

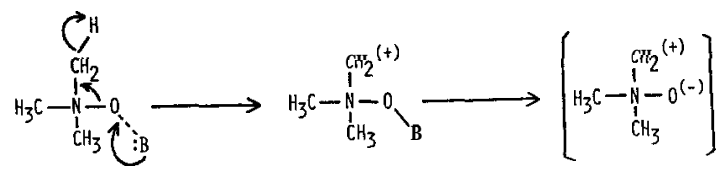

(B) Hydride ion

(a)

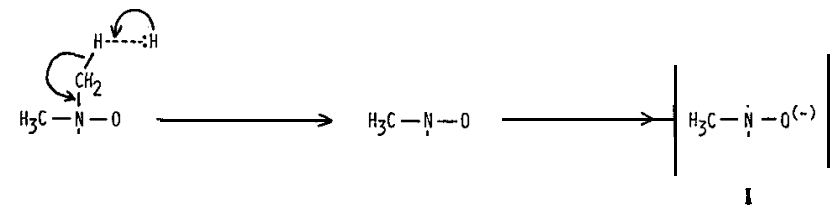

(b)

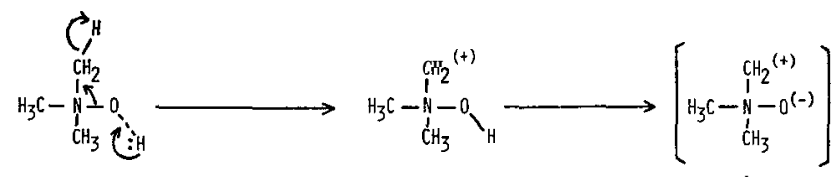

duction periods and the consumption of formed FA in the late stages. In order to explain such the specific features, several reaction schemes were assumed and their behaviors were simulated using digital computer. As a result, it is concluded that the induction periods were caused by the sequence of several reaction steps in the whole pathway, and that the formed FA was consumed in a slow rate by malonate in the catalyzer system,

It is, however, not likely that the reaction which is consisted of several reaction steps exhibits always the induction periods. The problems on the factors which cause the induction periods in reaction time-course will be discussed in the succeeding paper.

\section{ACKNOWLEDGEMENTS}

The authors wish to express their thanks to Dr. K. Yamada of The Shimonoseki University of Fisheries, for his valuable advices and discussions.

\section{REFERENCES}

Craig, J. C., F. B. Dwyer, A. N. Glazer and C. Horning 1961 Tertiary Amine Oxide Rearrangements. I. Mechanism. J. Am. Chem. Soc., 83: 1871-1878 
Dyer, W. J. and Y. A. Mounsey 1945 Amines in Fish Muscle II. Development of Trimethylamine and other Amines. J. Fish. Res. Bd. Canada, 6: 359-367

Fish, M. S., N. M. Johnson and E. C. Horning 1956 t-Amine Oxide Rearrangements. N, NDimethyltryptamines Oxide. J. Am. Chem. Soc., 78: 3668-3671

Frisell, W. R., C. W. Chung and C. G. Mackenzie 1959 Catalysis of Oxidation of Nitrogen Compounds by Flavin Coenzymes in the Presence of Light. J. Biol. Chem., 234: 1297-1302

Ferris, J. P., R. D. Gerwe and G. R. Gapski 1967 Detoxication Mechanism II. The IronCatalyzed Dealkylation of Trimethylamine Oxide. J. Am. Chem. Soc., 89: 5270-5275

Hayashi, Y., Y. Nagano, S. Hongyo and K. Teramura 1974 Trapping an Intermediate of the Polonovski Reaction. Tetrahedron Letters, 14 : 1299-1302

Nash, T. 1953 The Colorimetric Estimation of Formaldehyde by Means of the Hantzsch Reaction. Biochem. J., 55: 416-421

Sweely, C. C. and E. C. Horning 1957 Rearrangement and Decarboxylation Reactions of N, N-Dimethylglycine Oxide. J. Am. Chem. Soc., 79: 2620-2625

Soudan, F. 1959 Le Microdosage du Formol dans les Produits Marins. Rev. Trav. Inst. Pêches Marit., $23: 203-210$

Soudan,F.1961 Sobre la Presencia de Formol Natural en los Productos Marinos. Presented Paper at FAO International Conference on Fish in Nutrition, Washington, D. C., Sept., 19

Vaisey, E. B. 1956 The Non-Enzymic Reduction of Trimethylamine Oxide to Trimethylamine, Dimethylamine and Formaldehyde. Can. J. Biochem. Physiol., 34: 1085-1090

Yamada, K. 1967 Occurrence and Origin of Trimethylamine Oxide in Fishes and Marine Invertebrates. Bull. Jap. Soc. Sci. Fish., 33: 591-603

Yamada, K. 1968 Post-mortem Breakdown of Trimethylamine Oxide in Fishes and Marine Invertebrates. Bull. Jap. Soc. Sci. Fish., 34: 541-551 